\title{
Research on the Feasibility of Transversal Stiffeners Widening Structure in 3-way Prestressed Concrete Continuous Box Girder Bridge
}

\author{
Wu Wenqing ${ }^{1, \text { a }}$, Zhao Hao ${ }^{2, b}$ and Zhai Jianxun ${ }^{1, \mathrm{c}}$ \\ 1 Southeast University, Nanjing, China \\ 2 China Railway Engineering Consulting Group Co., Ltd.,Wuhan,China \\ a wqwuxu@163.com. b1217063315@qq.com cenacthao@163.com
}

\begin{abstract}
Keywords: 3-way Pre-stress Concrete box girder, Lateral widening, Stiffener, Foundation differential settlement.

Abstract. For the aim to solve the difficulty in 3-way prestressed concrete box girder bridge widening, a new flexible horizontal stitching structure based on the transverse stiffeners is proposed. The two flange plates between the existed box girder and new one will be separated structurally, but connected with a flexible stitching structure, which consists of s set of transverse concrete stiffeners spaced under the flange plates along the longitudinal direction. Based on a bridge widening practice, the mechanical performance of the flexible stitching structure and the existed box girder after widening are studied in detail, by considering the effect of vehicle load, foundation settlement, shrinkage and creep deformation of new concrete. Research shows that the structural stiffness of the whole structure after widening is obviously improved, and the live load effect of existed bridge can effectively be reduced, which shows that the transverse stiffener can effectively connect the new and old box girder, the widening structure can work as a joint structure. The influence of the size and spacing of stiffeners on the new and old bridges and stiffener itself is also studied. The results show that the flexible stiffener joint structure is feasible to broaden 3-way prestressed concrete box bridge, providing a new alternative scheme for similar bridge widening.
\end{abstract}

\section{Introduction}

When prestressed concrete box girder bridge widening, if the new box girder stitching directly, its flange slab usually need to be cut partly in longitudinal direct, to expand the cross-sectional area for transverse anchorage construction ${ }^{[1-2]}$. However, this stitching scheme does not apply to 3-way prestressed concrete continuous box girder bridges, because of the existence of transverse prestressed reinforcement. Therefore, there are no widely accepted widening schemes for the transverse widening of three direction prestressed concrete box girder bridges ${ }^{[3-4]}$.

To solve the problem of transverse splicing of 3-way prestressed concrete continuous box girder bridges under soft soil condition, this paper takes Yanhe River Bridge on Beijing Shanghai Expressway as the research object, and puts forward a new transverse splicing structure. In the premise of separation of old and new box girder flange structure, transverse stiffeners were arranged in new and old box beams longitudinally, connecting the old box beams, forming a transversely flexible structure, which is shown in Figure 4 and Figure 5. After the transverse joint of new and old box girder structures is completed, the transverse stiffening ribs are used as lateral transmission ways to transfer the interaction between new and old box girders, and at the same time, it can adjust to the larger differential settlement of old and new foundations. This scheme need not chisel flange edge anchored prestressed reinforcement, which is suitable for prestressed reinforcement box girder transverse widening. It can avoid the traffic safety problems caused by structural deformation and it is an effective structure, as long as appropriate structural stiffness be chosen. Due to the flexural rigidity of the stiffener is small and easy to be adjusted, it is very suitable for box girder bridge transverse widening in soft soil areas. This paper use finite element method analyzes the transverse stiffener under unfavorable load conditions.

The span of the Yanhe River Bridge is $(42+65+42) \mathrm{m}$, which is a 3 -way prestressed variable cross section continuous box girder bridge with cantilever cast-in-place construction. 
The original bridge uses two-way separation lane, the width of the single deck is $13.5 \mathrm{~m}$, and the width of the bridge deck is $20.5 \mathrm{~m}$ after the widening. The Stitching structure of Yanhe Bridge is shown in Fig.1. The stiffeners are arranged in a certain distance along the longitudinal direction of the structure, and the three-dimensional map of the stitching structure is shown in Fig.2. After the preliminary analysis, the size of the transverse stiffeners is preliminarily drawn as the height of $\mathrm{H}=30 \mathrm{~cm}$, the thickness of $\mathrm{B}=50 \mathrm{~cm}$, and the longitudinal spacing of $\mathrm{L}=4 \mathrm{~m}$, as shown in Fig. 2 .

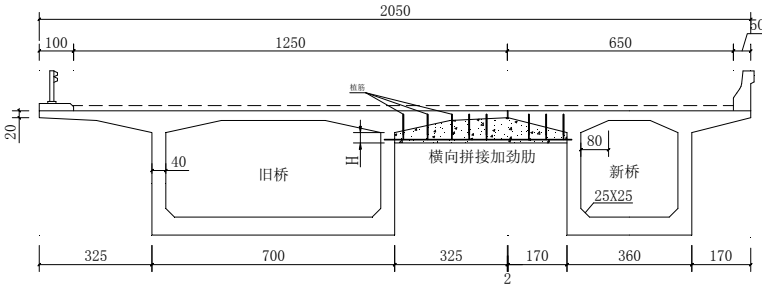

Fig.1 Stitching structure of Yanhe Bridge widening

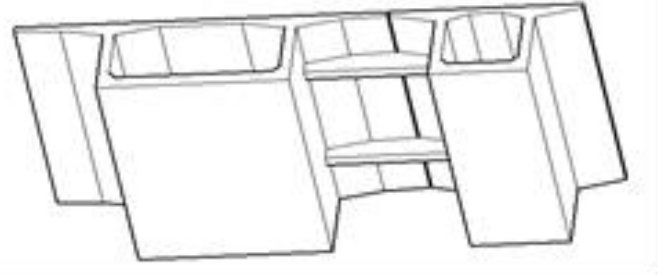

Fig.2 Three-dimensional map of the stitching structure

\section{Stress State after Widening}

The analysis mainly consider the combined effects of structure weight, prestress, shrinkage and creep effect, temperature gradient, uneven settlement of foundation and the vehicle load.

In order to establish grillage model, dividing diagram of the section longitudinally of Salt River Bridge is shown in fig. 3. In the structure calculation model, the total bridge is divided into 1813 units. The role of prestressed reinforcement is taken into account in the shear - flexible lattice model, and the material parameters are taken according to the original design requirements of the bridge. The support constraints of the lattice model are simulated by real bridge, as shown in Fig. 4.

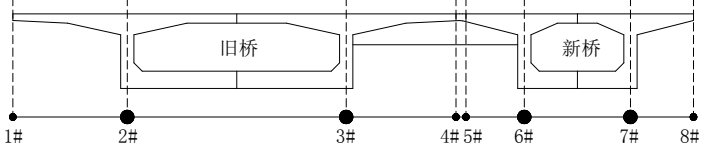

Fig.3 Beam grid partition diagram for widened box girder cross section of Salt River Bridge

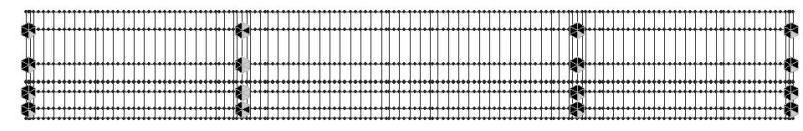

Fig.4 Plane dividing diagram for beam grid partition of Salt River Bridge

In the calculation and analysis, the middle longitudinal beam and the stiffener are the main control components. This paper will mainly analyze the stress status of the above components. The main control section has: $1 \#$ side support section, 2\# 1/4 side span section, 3\# 1/2 side span section, 4\# 3/4side span section, 5\# middle span section, 6\# 1/4middle span section and 7\#middle span section, as shown in Fig.5.

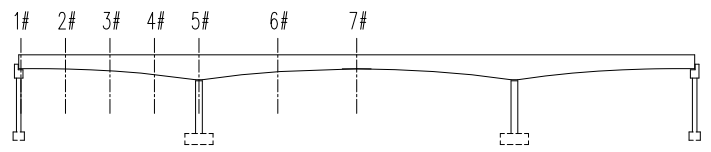

Fig.5 Schematic diagram of control section division for structure analysis

Table 1 and Table 2 show the bending moment and shear force of the main girder of the original bridge before and after widening.

Table 1 moment values of old bridges before and after widening (Unit: KN.m)

\begin{tabular}{ccccc}
\hline section & Before widening & after widening & Chang value & change rate \\
\hline $1 \#$ & -761 & -778 & -17 & $+2.23 \%$ \\
$3 \#$ & 21668 & 19055 & -2613 & $-12.06 \%$ \\
$5 \#$ & -136465 & -140995 & 4530 & $+3.32 \%$ \\
$7 \#$ & 49631 & 48384 & -1247 & $-2.51 \%$ \\
\hline
\end{tabular}


Table 2 shear value of original bridge before and after widening (unit: $\mathrm{kN}$ )

\begin{tabular}{ccccc}
\hline section & Before widening & after widening & change value & change rate \\
\hline $1 \#$ & 1964 & 2011 & 47 & $+2.38 \%$ \\
$3 \#$ & 4072 & 4074 & 3 & $+0.07 \%$ \\
$5 \#$ & 12179 & 13515 & 1337 & $+10.98 \%$ \\
$7 \#$ & 1304 & 1271 & -34 & $-2.59 \%$ \\
\hline
\end{tabular}

The results show that the internal forces of the box girder structure vary in sections before and after widening:

(1) Section bending moment: the negative bending moment of the supporting section increases slightly, the increase range is less than $3.3 \%$, and does not affect the structural safety. The positive bending moment of the middle section of each span decreases, such as the bending moment of the middle section of the side span decreases by $12.6 \%$.

(2) Shear force: the shear force at the key section has increased, for example, the shear force of $5 \#$ support section has increased by $10.98 \%$, while the change of shear force of other sections is very small. Nevertheless, the shear value of $5 \#$ middle section is still less than the shear capacity of the section after transverse widening, and the structure is still safe. Therefore, when transverse stiffeners are used for transverse widening, the flexural and shear capacity of each key section still meet design requirements, and there is no structural safety problem.

\section{Parameter Analysis of Stiffener}

In this chapter, the forces of the new and old box beams and stiffeners are analyzed when the height, width and spacing of stiffeners are changed, and the following conclusions are obtained:

(1) The internal force of the new and old box girder is hardly influenced by the change of the size of stiffeners. When the size (height and width) of the stiffener is changed, the change of maximum and minimum bending moment and shear force of old box girder is very small, the variation range is generally $5 \%$, and the maximum is less than $10 \%$.

(2) The size of stiffeners have great influence on the internal force of itself. Select 1\#-7\# control sections as shown in Fig.5, and analyze the maximum bending moment and maximum shear force of stiffener with different height and thickness. Fig. 6 shows the maximum bending moment of different height of stiffeners, Fig. 7 shows the maximum shear strength of different height of stiffeners, Fig. 8 shows the maximum bending moment diagram of different stiffeners, and Fig.9 shows the maximum shear force change diagram.

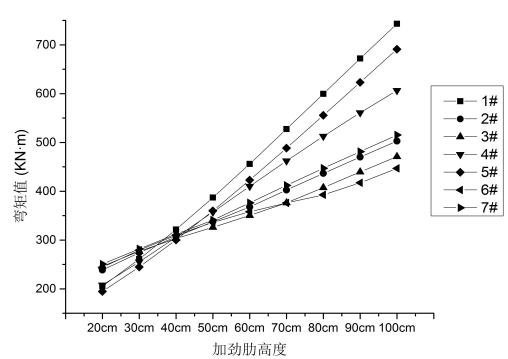

Fig.6 maximum bending moment of different height of stiffeners

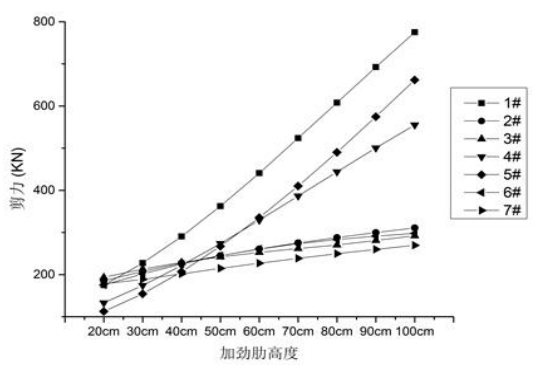

Fig.7 maximum shear strength of different height of stiffeners 


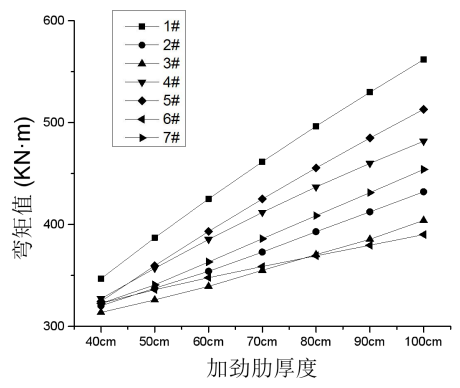

Fig. 8 maximum bending moment of different thickness of stiffeners

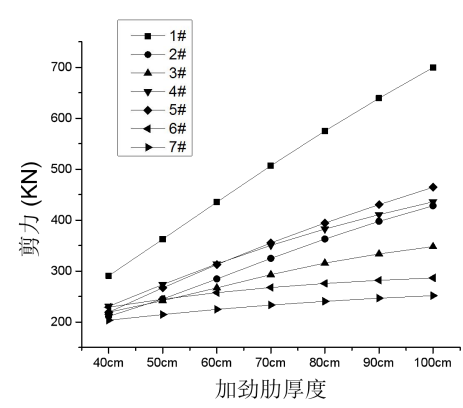

Fig.9 maximum shear thickness of different thickness of stiffeners

With the increase of the height and thickness of the stiffeners, the maximum bending moment and the maximum shear value of the spliced stiffeners increase significantly, with a large variation, up to $342 \%$ and a minimum of $23.8 \%$. When the sizes of the stiffeners are small, the values of maximum bending moment and shear of the joint stiffener are similar. With the increase of height and thickness of stiffeners, the maximum bending moment increased, the increase of internal force near the support section was most pronounced.

(3) The influence of different spacing of the stiffener is analyzed, using internal force of $4 \mathrm{~m}$ as benchmark " 1 ". Table 3 reflects the change of the internal force of stiffeners with different spacing. In the table, the maximum bending moment refers to the bending moment value and the corresponding shear value of the spliced stiffener under the maximum bending moment. Maximum shear stress is defined similarly; The average maximum bending moment refers to the average value of the maximum bending moment of all stiffeners under the comprehensive effect. The average maximum shear stress is defined similarly. From the table, we can see that the bending moment and shear force of every stiffener increase with the increase of the spacing, but the sum of bending moment and shear force of all stiffeners is reduced.

Table3 The internal force variation of stiffeners with different spacing

\begin{tabular}{|c|c|c|c|c|c|c|c|c|}
\hline \multirow{2}{*}{$\begin{array}{l}\text { Actual } \\
\text { spacing }\end{array}$} & \multirow{2}{*}{$\begin{array}{l}\text { Relative } \\
\text { spacing }\end{array}$} & \multirow{2}{*}{ Number } & \multicolumn{2}{|c|}{$\begin{array}{l}\text { Maximum bending } \\
\text { moment }\end{array}$} & \multicolumn{2}{|c|}{$\begin{array}{l}\text { Maximum shear } \\
\text { force }\end{array}$} & \multirow{2}{*}{$\begin{array}{c}\text { Average } \\
\text { maximum } \\
\text { bending } \\
\text { moment }\end{array}$} & \multirow{2}{*}{$\begin{array}{l}\text { Average } \\
\text { maximum } \\
\text { shear force }\end{array}$} \\
\hline & & & $\begin{array}{l}\text { bending } \\
\text { moment }\end{array}$ & $\begin{array}{l}\text { shear } \\
\text { force }\end{array}$ & $\begin{array}{l}\text { bending } \\
\text { moment }\end{array}$ & $\begin{array}{l}\text { shear } \\
\text { force }\end{array}$ & & \\
\hline $4 \mathrm{~m}$ & 1 & 1 & 1 & 1 & 1 & 1 & 1 & 1 \\
\hline $6 \mathrm{~m}$ & 1.5 & 0.67 & 1.050 & 0.974 & 1.029 & 1.024 & 1.136 & 1.230 \\
\hline $8 \mathrm{~m}$ & 2 & 0.5 & 1.177 & 1.155 & 0.700 & 1.162 & 1.239 & 1.415 \\
\hline $10 \mathrm{~m}$ & 2.5 & 0.4 & 1.422 & 1.462 & 0.902 & 1.481 & 1.387 & 1.691 \\
\hline
\end{tabular}

With the increase of the spacing, the efficiency of each stiffener is improved. It is important that the spacing cannot be increased blindly in the design, which needs to meet the requirements of strength and deformation of the structure.

\section{Conclusion}

(1) Compared to the old bridge box girder before the splicing, the overall stiffness of the structure after widening and splicing is obviously improved, and it can effectively reduce the live load effect of the old bridge. It shows that transverse stiffeners can effectively connect new and old box girders. After widening, the internal force of each key section of the existing box girder structure has changed, and its flexural and shear capacity still meet requirements, and there is no structural safety problem.

(2) The variation of stiffener size and spacing have little effect on the stress of the old and the new box girder, while it have a greater impact on the stress of the stiffener itself. Although the stiffener 
itself still has a large tensile stress, the design parameters need to be further optimized, but the method in this paper is still an alternative.

\section{References}

[1] Zhou Zonghong, Xia Zhanghua, Chen Yiyan, et al. State -of -the- art and engineering example analysis of longitudinal connection joints between the new bridge and existing bridge during widening and reconstructions. Journal of Fuzhou University, 2009 (2): 248-260.

[2] He Tiefei, Sun Tiegang. Research and analysis on seam processing method of existed bridge superstructure. City Bridge and Flood Control, 2012 (6): 228-230.

[3] Zhai Jianxun. Design and research of transverse expansion joint stiffening rib of concrete box girder bridge with large cantilever. Nanjing: Southeast University, 2016;

[4] Hao Shuguang. Design and experimental study on transverse joint structure of three-way prestressed continuous box girder bridge [D]. Nanjing: Southeast University, 2012. 